Article

\title{
Preparation and Characterization of Polydopamine-Modified Ni/Carbon Nanotubes Friction Composite Coating
}

\author{
Ye Wang ${ }^{1,2,+}$ and Jianfeng Chen ${ }^{1, *,+}$ \\ 1 School of Mechanical Engineering, Nanchang University, Nanchang 330031, China; \\ wangye9@mail.ustc.edu.cn \\ 2 USTC Center for Micro- and Nanoscale Research and Fabrication, University of Science and Technology of \\ China, Hefei 230026, China \\ * Correspondence: cjf@ncu.edu.cn \\ + These authors contributed equally to this work.
}

Received: 28 August 2019; Accepted: 12 September 2019; Published: 20 September 2019

check for updates

\begin{abstract}
In this paper, dopamine (DA) was used for the surface modification of carbon nanotubes (CNTs) to solve the agglomeration problem. High resolution transmission electron microscopy (HRTEM) and X-ray photoelectron spectroscopy (XPS) were utilized to understand the morphology and presence of different elements in the modified CNTs. The treated CNT surfaces were wrapped by a pDA layer and the layer thickness was controlled by reaction time. The dispersion test showed that the treated CNTs remained uniformly dispersed in solution for more than 30 days. The Ni/CNTs@pDA composite coating on the mild steel specimen was obtained by the electrodeposition technique. Ball-on-disc friction-wear equipment and an electrochemical workstation were used to test the friction-wear and corrosion resistance of the composite coating. The results indicated that the Ni/CNTs@pDA coating showed excellent tribological performance and were superior to the pure Ni coating.
\end{abstract}

Keywords: carbon nanotubes; dopamine; surface modification; composite coating; friction-wear; corrosion resistance

\section{Introduction}

As a kind of one-dimensional nanomaterial, carbon nanotubes (CNTs) [1] have excellent mechanical properties [2,3], super toughness, a unique physical structure, electrical, physical, and chemical properties. Composite coatings with added nanomaterials such as carbon nanotubes, nano $\mathrm{Al}_{2} \mathrm{O}_{3}[4-6]$, $\mathrm{SiC}$ [6,7], $\mathrm{TiO}_{2}$ [8], and WC [9] have better friction and wear properties and corrosion resistance than the non-added composite coating. As a reinforcement, CNTs improve the friction and wear characteristics of a composite coating $[10,11]$. For example, Ni/CNT composite coatings have a higher wear resistance and lower friction coefficient [12] than a pure Ni coating. However, due to their unique structures and their smooth surfaces, which are hard to effectively bind with the matrix, CNTs are extremely easy to reunite in solution, which seriously affects the overall performance of the coating. Therefore, the agglomeration of CNTs in solution and the binding strength between CNTs and the substrate are urgent problems for metal based CNT composite coatings. As a result, it is necessary to modify CNT surfaces to improve their dispersion characteristic. Methods of surface modification for CNTs are mainly categorized as non-covalent and covalent modifications [13-16]. Non-covalent modification includes mechanical grinding [17] and ultrasonic vibration [18], while covalent modification utilize oxidation [19] and chemical modification [20]. Generally, non-covalent modification is easy to operate, but has a poor modification efficiency. In contrast, covalent modification can significantly increase the 
modification efficiency, however, the structure of the CNTs may be destroyed. Therefore, it is a key problem to find a simple and effective way to modify CNTs.

Recently, dopamine (DA) is studied as a promising bio-inspired material for coating modification. The catechol groups and the amino functional groups in DA give it a strong adhesion ability. In addition, a polymer named polydopamine (pDA) can be generated via the oxidative self-polymerization of DA and is deposited on the surface of organic, inorganic, and other materials [21-24]. Bin et al. [22,25] used DA to modify CNTs, while the CNT structure was not damaged. Furthermore, pDA contains hydroxyl, amino, and other hydrophilic functional groups, which can significantly improve the hydrophilic properties. It has been reported that pDA modification extremely improved the dispersion of multi-walled carbon nanotubes (MWNTs) and that the modified MWCNTs were dispersed uniformly in an aqueous solution for more than 30 days [25]. More importantly, the pDA layer can act as the second reaction platform. In particular, the metal-binding ability of catechol groups can absorb and reduce metal ions to the surface that is coated with a pDA layer. Sureshkumar et al. [26] used pDA to reduce nanosilver particles to different surfaces. Their study suggested the successful immobilization of AgNPs with good stability, and that the surfaces immobilized with AgNPs possessed good antibacterial and biocompatibility properties. However, as far as we know, studies on preparing Ni/CNTs composite coatings utilizing the surface modification of DA to disperse CNTs and enhance the bonding force between CNTs and Ni matrix have not been reported.

In this study, DA was used to modify the CNTs and the CNTs@pDA composite coating was prepared by the electrodeposition technique. The friction-wear and corrosion properties of the coating were tested. In the experiment, HRTEM and XPS confirmed that the treated surfaces of the CNTs were wrapped with the pDA layer and the thickness of the pDA layer was controlled by the reaction time. The surface morphology of the CNTs and coatings was observed by scanning electron microscope (SEM). Their chemical composition was characterized by x-ray photoelectron spectroscopy (XPS) and energy spectrometer (EDS). The friction-wear and corrosion resistance of the coating were tested by ball-on-disc equipment and an electrochemical workstation. The results showed that the dispersion of CNTs@pDA was significantly improved and that the friction-wear and corrosion properties of the composite coatings were better than the pure Ni coating.

\section{Materials and Methods}

\subsection{Materials}

Carbon nanotubes ( $\geq 98 \%$ ) with a diameter of about 15 to $25 \mathrm{~nm}$ and a length of about 1 to 20 microns were supplied by Jiangsu Suzhou Hengqiu Technology Co. Ltd. Dopamine hydrochloride ( $\geq 98 \%$ ) was purchased from Shanghai Macklin Biochemical Technology Co. Ltd. Tris-(hydroxymethyl)-aminomethane ( $\geq 99.5 \%$ ) was supplied from Shanghai Jinsui Bio-Technology Co. Ltd. The plating bath of the Ni coatings was provided by Wuhan Material Protection Research Institute.

\subsection{Modification of CNTs@pDA}

The schematic of the modification of CNTs@pDA was shown in Figure 1. First, the CNTs (500 mg) were added into an aqueous solution $(500 \mathrm{~mL})$. Then, the solution was stirred by a magnetic mixer for $10 \mathrm{~min}$ and vibrated by ultrasonic vibration (power: $100 \mathrm{w}$ ) for $30 \mathrm{~min}$. Next, Tris $(0.605 \mathrm{~g})$ was added into the solution. Prior to adding DA $(1000 \mathrm{mg})$ into the solution, the $\mathrm{pH}$ of the solution was adjusted to $8.5 \mathrm{by} \mathrm{HCl}$. The content of DA was fixed at $2 \mathrm{~g} / \mathrm{L}$. After stirring the mixture at room temperature for $6,12,18$, and $24 \mathrm{~h}$, respectively, the CNT surfaces were wrapped by a layer of $\mathrm{pDA}$, which is the product of the oxidative self-polymerization reaction of DA in a weak alkaline environment. Finally, CNTs@pDA was acquired, which was filtered and washed repeatedly with distilled water and dried at $50{ }^{\circ} \mathrm{C}$ for $10 \mathrm{~h}$. Different times, namely $6,12,18$, and $24 \mathrm{~h}$, were selected to study the influence of different reaction time on the composite coatings. The number of modified CNTs was represented by CNTs@pDA-\# (\# represents the reaction time of the CNTs and DA, namely 6, 12, 18, and $24 \mathrm{~h}$ ). 


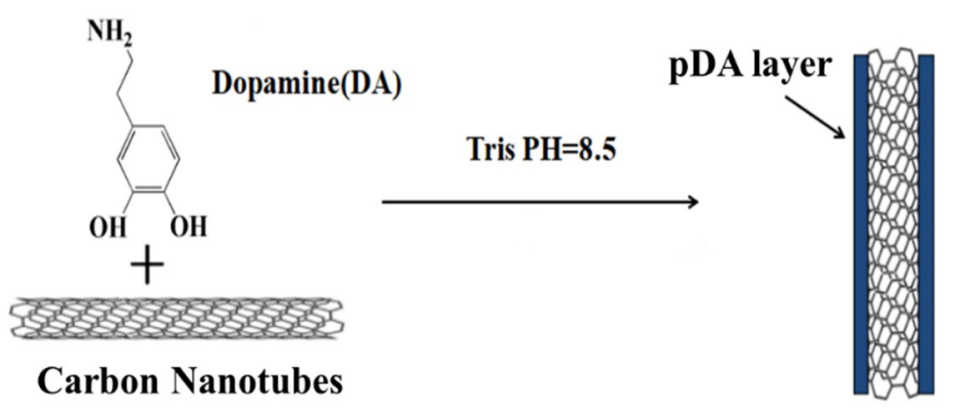

Figure 1. The schematic of the binding of dopamine to the carbon nanotubes. Under the condition of a Tris solution of $\mathrm{pH} 8.5, \mathrm{pDA}$ was generated and bonded to the CNTs through the oxidative self-polymerization reaction.

The schematic illustration of modifying CNTs with DA (Figure 1) shows that DA undergoes an oxidative self-polymerization reaction in a weak alkaline environment with $\mathrm{pH}=8.5$, and the $\mathrm{pDA}$ layer forms on the surfaces of CNTs, giving them the hydrophobicity and chemical activity.

\subsection{Preparation of Ni/CNTs@pDA Composite Coating}

Ni/CNTs@pDA composite coatings were obtained by electrodeposition. The deposition process was carried out on a circular medium carbon steel plate $(r \times h: 3 \mathrm{~cm} \times 2 \mathrm{~mm})$. The component of the coating solution was as follows: $\mathrm{NiSO}_{4} \cdot 6 \mathrm{H}_{2} \mathrm{O} 250 \mathrm{~g} / \mathrm{L}, \mathrm{HBO}_{3} 40 \mathrm{~g} / \mathrm{L}, \mathrm{NiCl}_{2} \cdot \mathrm{H}_{2} \mathrm{O} 35 \mathrm{~g} / \mathrm{L}$, and CNTs@pDA $2 \mathrm{~g} / \mathrm{L}$. The $\mathrm{pH}$ of the solution was adjusted to 4.5 and the temperature was $48{ }^{\circ} \mathrm{C}$. During the electrodeposition process, the current density was maintained at $4 \mathrm{~A} / \mathrm{dm}^{2}$. Then, the CNTs@pDA composite coatings were obtained with a thickness of about $30 \mu \mathrm{m}$. The pure Ni coating was produced under the same condition for a comparison with the same composites.

\subsection{Characterization of CNTs@pDA}

X-ray photoelectron spectroscopy (XPS, ESCALAB250Xi, Thermo Fisher Scientific Company, Waltham, MA, USA) and energy dispersive spectroscope (EDS, JSM-6701F, JEOL Ltd., Tokyo, Japan) was utilized to analyze the chemical elements of CNTs@pDA. The surface morphology of the CNTs and coatings was characterized by high resolution transmission electron microscope (HRTEM, JEM-2100, JEOL Ltd.). The dispersibility of CNTs and CNTs@pDA in aqueous solution (2.0 g/L) was observed and compared at different times.

\subsection{Friction-Wear and Corrosion Tests of Ni/CNTs@pDA Composite Coating}

Friction and wear properties of the composite coating were investigated using the ball-on-disc method under the condition of room temperature. The diameter and hardness of the GCr15 ball was $11 \mathrm{~mm}$ and 60-63 HRC. The speed, time, and load were kept at $0.5 \mathrm{~m} / \mathrm{min}, 400 \mathrm{~s}$, and $4 \mathrm{~N}$, respectively. The mass loss was measured with an analytical balance. The worn surfaces of the coated specimens were observed by scanning electron microscopy. The electrochemical corrosion detection was implemented in a $\mathrm{CHI} 660 \mathrm{E}$ electrochemical workstation at $25 \pm 2{ }^{\circ} \mathrm{C}$. The coated specimens, platinum electrode, and saturated calomel electrode were used as the working, auxiliary, and reference electrodes, respectively. The detection area of the coating was $1 \mathrm{~cm}^{2}$ and were measured in $3.5 \% \mathrm{NaCl}$ solution to acquire the polarization curve. Corrosion potential and corrosion current density were obtained by fitting the polarization curve. 


\section{Results and Discussions}

\subsection{Surface Morphology of CNTs@pDA}

The high resolution transmission electron microscope (HRTEM) images (Figure 2) showed that the treated CNT surfaces with the DA modification were wrapped with a layer. The thickness of the layer was controlled by the reaction time. It can be seen that the thickness increased with the reaction time. When the reaction time between DA and CNTs was $6 \mathrm{~h}$, there were several particles absorbed on the CNT surfaces. The surfaces could be fully wrapped by the layer when the reaction time was over $12 \mathrm{~h}$.
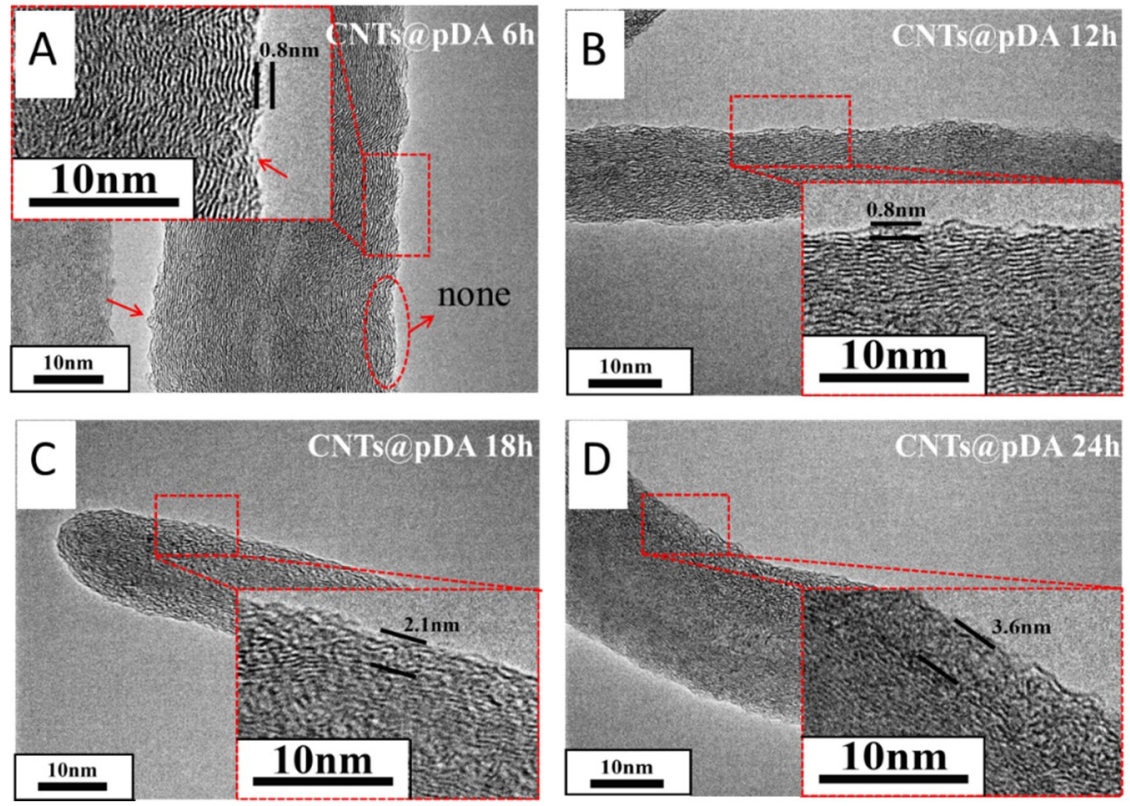

Figure 2. High resolution transmission electron microscope (HRTEM) image of CNTs@pDA at different modification times $(6,12,18$, and $24 \mathrm{~h}$, respectively). (A) The image of CNTs@pDA modified over $6 \mathrm{~h}$. The wall of the CNTs was partially modified by pDA. The enlargement image showed that the thickness of the deposited pDA was $0.8 \mathrm{~nm}$. (B) The image of CNTs@pDA modified over $12 \mathrm{~h}$. The wall of the CNTs was completely modified. The thickness of the deposited pDA was still $0.8 \mathrm{~nm}$. (C) The image of CNTs@pDA modified over $12 \mathrm{~h}$. The pDA thickness increased to $2.1 \mathrm{~nm}$. (D) The image of CNTs@pDA modified over $24 \mathrm{~h}$. The thickness of the pDA was $3.6 \mathrm{~nm}$. The scale bar was $10 \mathrm{~nm}$.

\subsection{XPS Detection of CNTs@pDA}

X-ray photoelectron spectroscopy was utilized to detect the chemical elements of modified CNTs. The results of the XPS spectra of the original CNTs and CNTs with the surface modification of DA up to $12 \mathrm{~h}$ were tested and are shown in Figure 3, respectively. The original CNTs only had their unique elements: $\mathrm{C}$ and $\mathrm{O}$. Due to its unique one-dimensional six-membered ring structure and hollow nanotubes, the oxygen content of CNTs without other active groups was low. It was worth noting that a significant N-element absorption peak appeared at about $400 \mathrm{eV}$ in the spectra of CNTs with the surface modification of DA. The N-element is the endemic element of the amino group in DA. Additionally, pDA contains hydroxyl groups and other oxygen containing groups that resulted in the increase of oxygen content in the CNTs. The peak of the $\mathrm{O}$ element became higher and the activity of the CNTs increased. From Figure 3A,B, it can be seen that the original CNTs mainly consisted of $\mathrm{C}-\mathrm{C} / \mathrm{C}=\mathrm{C}, \mathrm{C}-\mathrm{O}$ and some $\mathrm{C}=\mathrm{O}$ bonds. Aside from the above-mentioned functional groups, CNTs@pDA had $\mathrm{C}-\mathrm{N}$ bonds and a higher $\mathrm{C}-\mathrm{O}$ peak than the original CNTs. This further proved that CNTs were successfully wrapped by a layer of pDA. 

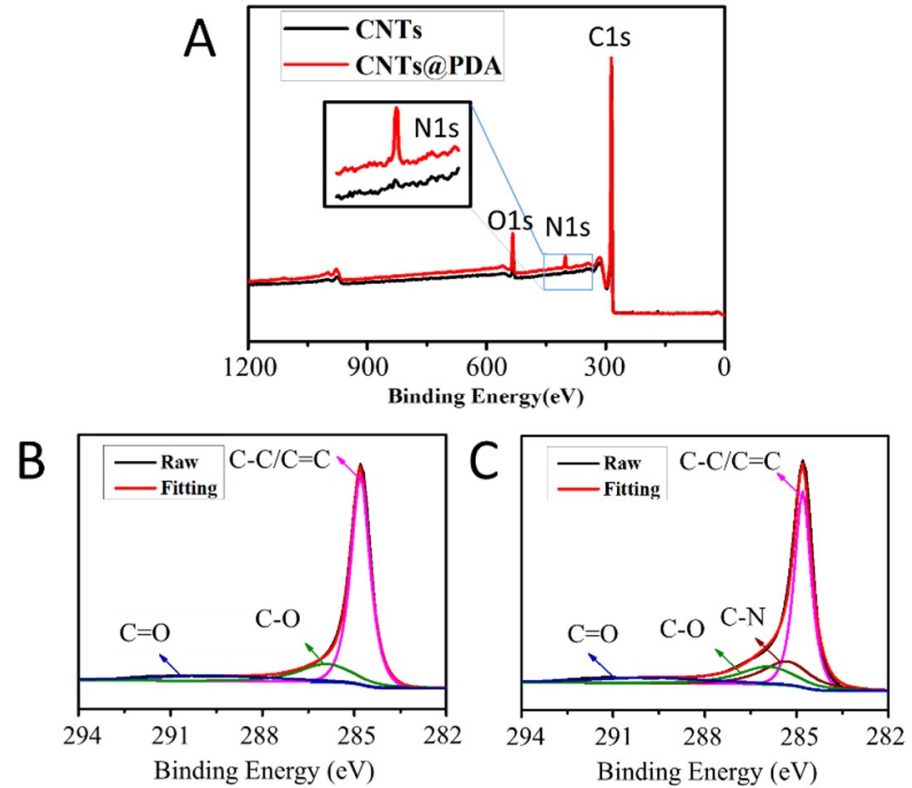

Figure 3. The x-ray photoelectron spectroscopy of pure CNTs and CNTs@pDA. (A) The elemental analysis of pure CNTs and CNTs@pDA. Compared with the spectra of pure CNTs, the spectra of CNTs@pDA had a significant N-element absorption peak appeared at about $400 \mathrm{eV}$ and a higher O-element absorption peak. (B) The XPS spectroscopy of the bond between the elements of pure CNTs. (C) The XPS spectroscopy of the bond between the elements of CNTs@pDA. Compared with the results of pure CNTs, there was a C-N bond in CNTs@pDA.

\subsection{Dispersion Observation of CNTs}

Figure 4 showed that after 30 min of ultrasonic vibration, CNTs without any treatment reunited and precipitated soon due to their high ratio of length to diameter and high surface energy. Correspondingly, the CNTs with the surface modification of DA remained as a dispersion in solution for more than 30 days. This is because the surfaces of CNTs were wrapped with a layer of $\mathrm{pDA}$, which is hydrophilic and has a unique catechol structure of DA. Under different modification times, four kinds of CNTs@pDA had nearly the same dispersion. The pDA modification ensures that CNTs disperse evenly in the bath, which is the key to acquiring a high quality composite coating.
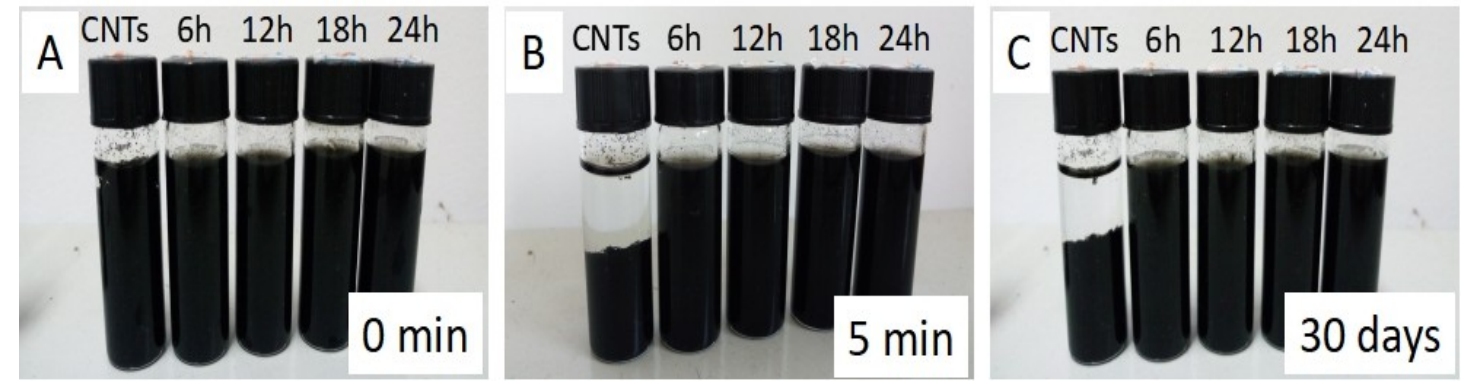

Figure 4. Image of the dispersion of pure CNTs and CNTs@pDA modified at different times $(6,12,18$, and $24 \mathrm{~h}$ ). (A) Image of the dispersion of the samples at the initial time. (B) Image of the dispersion of the samples after 5 min settling time where the pure CNTs had subsided and CNTs@pDA maintained a dispersed state. (C) Image of the dispersion of the samples after 30 days settling time where the CNTs@pDA still maintained its dispersion.

\subsection{CNTs@pDA Deposition}

To study the deposition mechanism of DA-treated CNTs in the process of preparing a composite coating, the quantitative CNTs and CNTs@pDA-12h were dispersed in the plating bath at a concentration 
of $2 \mathrm{~g} / \mathrm{L}$. After $30 \mathrm{~min}$ of ultrasonic vibrating, the plating bath was stood for $24 \mathrm{~h}$ at room temperature, followed by suction filtration, washing, and vacuum drying. As shown in Figure 5, the EDS test result indicated that the content of $\mathrm{Ni}$ in the CNTs without the modification of DA was 3.53\%. As the plating bath contained a certain amount of reducing agent, part of the $\mathrm{Ni}^{2+}$ was reduced and deposited on the surfaces of CNTs, so they contained a certain amount of the Ni element. However, the Ni content of the CNTs@pDA-12h surface soaked in an electroplating bath for $24 \mathrm{~h}$ reached up to $9.25 \%$. During the immersion process, in addition to the reduction performance of the plating solution, the pDA layer also had certain reducibility, which resulted in a large amount of $\mathrm{Ni}^{2+}$ being reduced to $\mathrm{Ni}$ atoms and adhering to the surface of CNTs@pDA. This indicates that the effect of the electric field on the deposition of CNTs@pDA will be strengthened, thus CNTs@pDA was promoted to adsorb on the cathode surface rapidly and constantly.
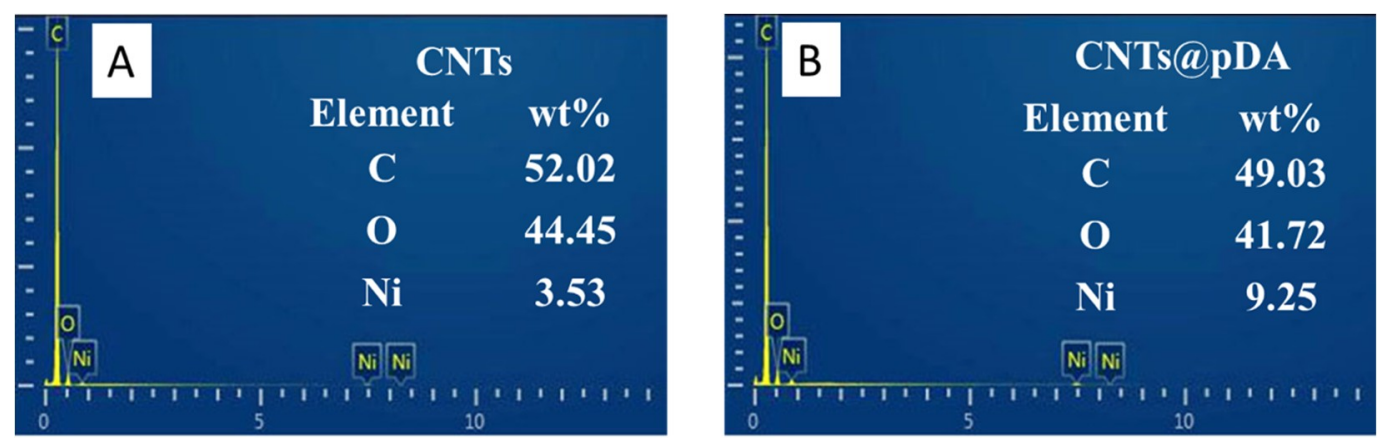

Figure 5. Image of the energy disperse spectroscopy (EDS) test of CNTs and CNTs@pDA dispersed in the electroplating bath for $24 \mathrm{~h}$. After dispersed in the electroplating bath for $24 \mathrm{~h}$, the mass fraction of $\mathrm{Ni}$ in CNTs@pDA (B) was higher than that of the original CNTs (A).

\subsection{Surface Analysis}

Figure 6A shows that the surface of the pure Ni coating was smooth. Plenty of small typical cluster crystals with a cauliflower shape could be seen. There were some microcracks and pores on them, which were caused by high internal stress in the coating and the phenomenon of hydrogen evolution during the electrodeposition process. Compared with the pure Ni coating, the surfaces of the Ni/CNTs@pDA composite coatings (Figure 6B-E) were more compact and the number of microcracks and pores was less than that of the pure Ni coating. The refining effect of grain was obvious. This is because the added CNTs can act as a heterogeneous nucleus to increase the nucleation rate and effectively restrain the over-growth of the grain.

\subsection{Friction and Wear Behavior}

Figure 7A,B showed the friction coefficient and wear loss of the Ni and Ni/CNTs@pDA coatings at a sliding speed of $0.5 \mathrm{~m} / \mathrm{s}$ and a load of $4 \mathrm{~N}$ under dry friction. The fraction coefficient and wear loss of the Ni/CNTs@pDA coating were both lower than that of the Ni coating. Due to the self-lubrication of CNTs, it could effectively decrease the friction factor. The thickness of the pDA layer seems to have no measurable impact on the friction coefficient of the coatings. As the dispersion of the CNTs@pDA was improved, it could uniformly distribute in the solution and in the composites. CNTs@pDA can act as heterogeneous nucleation, thus the crystalline grains of the composites are refined. The surfaces of the composites were more compact, the crystalline grains could share the load, and the wear loss of the composites was significantly reduced. From Figure 7B, it can be seen that the wear resistance of the composite coating became better as the thickness of the pDA layer increased. This further indicates that due to the strong adhesion of $\mathrm{pDA}$, the bonding strength between the CNTs and Ni matrix was enhanced, so the strength of the composite was improved and the wear resistance was better. 

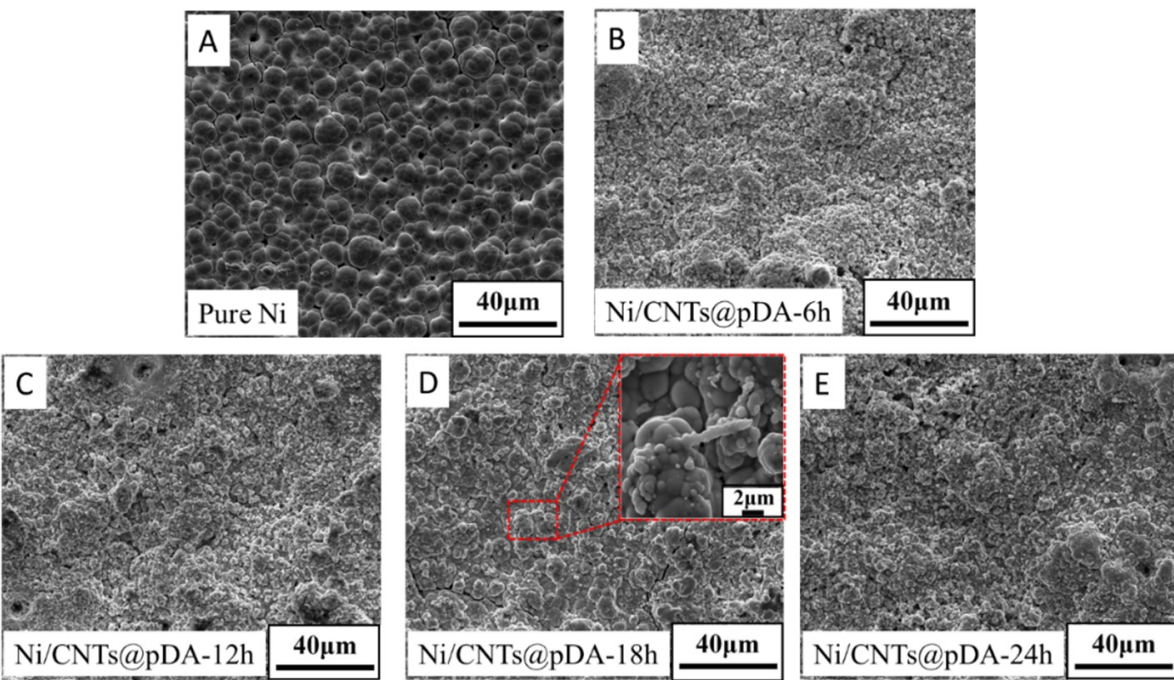

Figure 6. Scanning electron microscope (SEM) image of the surface of the Ni/CNTs@pDA composite coatings. (A) The image of the pure Ni coating. (B-E) The image of the surface of the Ni/CNTs@pDA composite coating with different pDA modification times $(6,12,18$, and $24 \mathrm{~h}$, respectively). The grain size of the Ni/CNTs@pDA composite coatings was smaller than that of the pure Ni coating.
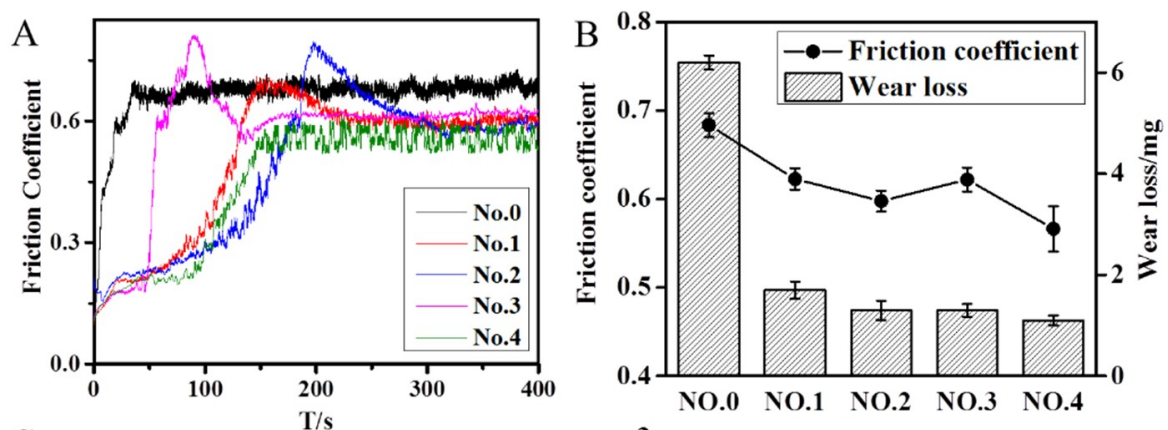

C
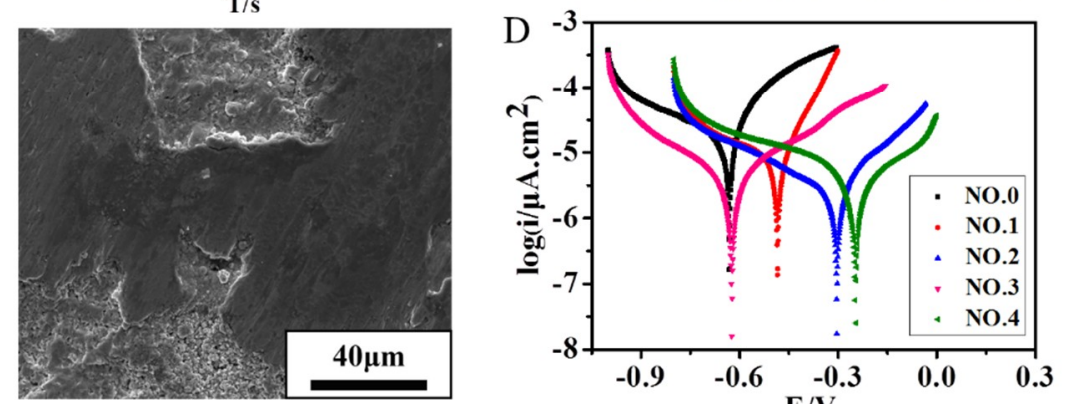

E

\begin{tabular}{|c|c|c|c|c|c|}
\hline & No.0 & No.1 & No.2 & No.3 & No.4 \\
\hline $\mathrm{E} / \mathrm{V}$ & -0.631 & -0.485 & -0.304 & -0.624 & -0.247 \\
\hline $\operatorname{Corssi}\left(\mu \mathrm{A} / \mathrm{cm}^{2}\right)$ & 30.44 & 10.64 & 4.832 & 4.11 & 4.097 \\
\hline
\end{tabular}

Figure 7. The friction-wear and corrosion tests of the coatings (No.0-No.4 refer to the Ni and Ni/CNTs@pDA-6, 12, 18, and 24 h coatings). (A) The image of the friction coefficient curve of several coatings. (B) The image of the friction coefficient and wear loss of several coatings. (C) The SEM image of the worn scar of the PDA@CNTs/Ni composite coatings. (D) The polarization curve of several coatings acquired by electrochemical detection. (E) The corrosion current density of the coatings obtained by fitting the polarization curve.

The worn surface morphology of the Ni/CNTs@pDA coating under the dry fraction condition is shown in Figure 7C. It can be seen clearly that on the surface, the main type of damage to the coating 
was adhesive wear. This may be because in the early stage of friction, the microbulge deformed first under the action of compressive stress and transverse shear stress. In the subsequent process of friction, due to the adhesion of $\mathrm{pDA}$, the falling debris still adhered to the surface of the coating and stacked continuously under the action of the circulating load.

\subsection{Corrosion Resistance}

A Tafel plot was carried out to evaluate the corrosion behavior of the Ni and Ni/CNTs@pDA coatings. The specimens were immersed in $3.5 \% \mathrm{NaCl}$ solution for $400 \mathrm{~s}$ to attain the equilibrium potential. Then, the electrodes were polarized from the cathodic to anodic direction at a scan rate of $10^{-3} \mathrm{Vs}^{-1}$. The corrosion current density and corrosion potential (Figure 7E) were determined by extrapolating the linear portion of the anodic and cathodic curves (Figure 7D). It can be observed from the figure that the curves of the composite coatings shifted to a more positive potential compared to that of the Ni coating. The results showed that the corrosion potential and corrosion current density of the Ni/CNTs@pDA composite coatings were both lower than that of the pure nickel coating. The corrosion current density was reduced by an order of magnitude. These indicate the better corrosion resistance of the composite coating. As the Ni/CNTs@pDA composite coatings were more compact than the pure nickel coating, the number of microcavities and cracks on the surface of the composites was reduced. The corrosion medium finds it difficult to enter the composites in the process of electrochemical corrosion. Moreover, CNTs with low chemical activity can play a certain hampering role in the corrosion process and pDA has a certain corrosion resistance [27]. As can be seen, with the increase in the thickness of the pDA layer, the corrosion resistance of the composite coating gradually became better.

\section{Conclusions}

The Ni/CNTs composite coating was prepared based on the modification of DA by the electrodeposition technique. HRTEM and XPS confirmed that the CNTs were wrapped by a pDA layer, which was the product of the oxidative self-polymerization reaction of DA. On one hand, the pDA layer improved the dispersion of CNTs in aqueous solution, and on the other hand, it acted as a second reaction platform on which the $\mathrm{Ni}^{2+}$ could be absorbed and reduced. EDS indicated that the Ni nanoparticles were immobilized on the surface of the CNTs. The results of the friction wear and corrosion test showed that with the increase in the thickness of the pDA layer, the properties of the composite coating improved greatly. This facile and green technique to prepare Ni/CNTs@pDA composite coatings is also suitable for other nanomaterials to prepare various metal-nanomaterial composites for future applications.

Author Contributions: Conceptualization, J.C. and Y.W.; methodology, Y.W.; writing—original draft preparation, Y.W.; writing-review and editing, J.C.

Funding: This work was supported by the National Natural Science Foundation of China (No. 51905248).

Conflicts of Interest: The authors declare no conflict of interest.

\section{References}

1. Iijima, S. Helical microtubules of graphitic carbon. Nature 1991, 354, 56-58. [CrossRef]

2. Lee, C.; Wei, X.; Kysar, J.W.; Hone, J. Measurement of the elastic properties and intrinsic strength of monolayer graphene. Science 2008, 321, 385-388. [CrossRef] [PubMed]

3. Alandin, A.A. Thermal properties of graphene and nanostructured carbon materials. Nat. Mater. 2011, 10, 569-581. [CrossRef] [PubMed]

4. Ciubotariu, A.C.; Benea, L.; Lakatos Varsanyi, M.; Dragan, V. Electrochemical impedance spectroscopy and corrosion behaviour of $\mathrm{Al}_{2} \mathrm{O}_{3}-\mathrm{Ni}$ nano composite coatings. Electrochim. Acta 2008, 53, 4557-4563. [CrossRef]

5. Alirezaei, S.; Monirvaghefi, S.M.; Salehi, M.; Saatchi, A. Effect of alumina content on surface morphology and hardness of Ni-P-Al $\mathrm{O}_{3}(\alpha)$ electroless composite coatings. Surf. Coat. Tech. 2004, 184, 170-175. [CrossRef] 
6. Dehgahi, S.; Amini, R.; Alizadeh, M. Corrosion, passivation and wear behaviors of electrodeposited $\mathrm{Ni}-\mathrm{Al}_{2} \mathrm{O}_{3}-\mathrm{SiC}$ nano-composite coatings. Surf. Coat. Tech. 2016, 304, 502-511. [CrossRef]

7. Vaezi, M.R.; Sadrnezhaad, S.K.; Nikzad, L. Electrodeposition of Ni-SiC nano-composite coatings and evaluation of wear and corrosion resistance and electroplating characteristics. Colloids Surf. A Physicochem. Eng. Asp. 2008, 315, 176-182. [CrossRef]

8. Parida, G.; Chaira, D.; Chopkar, M.; Basu, A. Synthesis and characterization of $\mathrm{Ni}^{-} \mathrm{TiO}_{2}$ composite coatings by electro-co-deposition. Surf. Coat. Tech. 2011, 205, 4871-4879. [CrossRef]

9. Benea, L.; Başa, S.; Dănăilă, E.; Caron, N.; Raquet, O.; Ponthiaux, P.; Celis, J. Fretting and wear behaviors of $\mathrm{Ni}$ /nano-WC composite coatings in dry and wet conditions. Mater. Des. 2015, 65, 550-558. [CrossRef]

10. Zarebidaki, A.; Allahkaram, S. Effect of surfactant on the fabrication and characterization of Ni-P-CNT composite coatings. J. Alloy. Compd. 2011, 509, 1836-1840. [CrossRef]

11. Suzuki, T.; Konno, T. Improvement in tool life of electroplated diamond tools by Ni-based carbon nanotube composite coatings. Precis. Eng. 2014, 38, 659-665. [CrossRef]

12. Chen, X.H.; Chen, C.S.; Xiao, H.N.; Liu, H.B.; Zhou, L.P.; Li, S.L.; Zhang, G. Dry friction and wear characteristics of nickel/carbon nanotube electroless composite deposits. Tribol. Int. 2006, 39, 22-28. [CrossRef]

13. Karousis, N.; Tagmatarchis, N.; Tasis, D. Current progress on the chemical modification of carbon nanotubes. Chem. Rev. 2010, 110, 5366-5397. [CrossRef] [PubMed]

14. Le, V.T.; Ngo, C.L.; Le, Q.T.; Ngo, T.T.; Nguyen, D.N.; Vu, M.T. Surface modification and functionalization of carbon nanotube with some organic compounds. Adv. Nat. Sci. Nanosci. Nanotechnol. 2013, 4, 035017. [CrossRef]

15. Mahmoodian, H.; Moradi, O.; Shariatzadeh, B. Grafting chitosan and polyHEMA on carbon nanotubes surfaces: "Grafting to" and "Grafting from" methods. Int J. Biol. Macromol. 2014, 63, 92-97. [CrossRef] [PubMed]

16. Poochai, C.; Pongprayoon, T. Enhancing dispersion of carbon nanotube in polyacrylonitrile matrix using admicellar polymerization. Colloids Surf. A Physicochem. Eng. Asp. 2014, 456, 67-74. [CrossRef]

17. Pierard, N.; Fonseca, A.; Colomer, J.; Bossuot, C.; Benoit, J.M.; Tendeloo, G.V.; Pirard, J.; Nagy, J.B. Ball milling effect on the structure of single-wall carbon nanotubes. Carbon 2004, 42, 1691-1697. [CrossRef]

18. Huang, W.; Lin, Y.; Taylor, S.; Gaillard, J.; Rao, A.A.M.; Sun, Y. Sonication-assisted functionalization and solubilization of carbon nanotubes. Nano. Lett. 2002, 2, 231-234. [CrossRef]

19. Wepasnick, K.A.; Smith, B.A.; Schrote, K.E.; Wilson, H.K.; Diegelmann, S.R.; Fairbrother, D.H. Surface and structural characterization of multi-walled carbon nanotubes following different oxidative treatments. Carbon 2011, 49, 24-36. [CrossRef]

20. Chen, C.S.; Chen, X.H.; Xu, L.S.; Yang, Z.; Li, W.H. Modification of multi-walled carbon nanotubes with fatty acid and their tribological properties as lubricant additive. Carbon 2005, 43, 1660-1666. [CrossRef]

21. Lee, H.; Dellatore, S.M.; Miller, W.M.; Messersmith, P.B. Mussel-inspired surface chemistry for multifunctional coatings. Science 2007, 318, 426-430. [CrossRef] [PubMed]

22. Fei, B.; Qian, B.; Yang, Z.; Wang, R.; Liu, W.C.; Mak, C.L.; Xin, J.H. Coating carbon nanotubes by spontaneous oxidative polymerization of dopamine. Carbon 2008, 46, 1795-1797. [CrossRef]

23. Liao, Y.; Cao, B.; Wang, W.; Zhang, L.; Wu, D.; Jin, R. A facile method for preparing highly conductive and reflective surface-silvered polyimide films. Appl Surf. Sci. 2009, 255, 8207-8212. [CrossRef]

24. Xi, Z.; Xu, Y.; Zhu, L.; Wang, Y.; Zhu, B. A facile method of surface modification for hydrophobic polymer membranes based on the adhesive behavior of poly(DOPA) and poly(dopamine). J. Membr. Sci. 2009, 327, 244-253. [CrossRef]

25. Jiang, Y.; Lu, Y.; Zhang, L.; Liu, L.; Dai, Y.; Wang, W. Preparation and characterization of silver nanoparticles immobilized on multi-walled carbon nanotubes by poly(dopamine) functionalization. J. Nanopart Res. 2012, 14. [CrossRef]

26. Sureshkumar, M.; Siswanto, D.Y.; Chen, Y.; Lee, C.; Wang, M. Antibacterial and biocompatible surfaces based on dopamine autooxidized silver nanoparticles. J. Polym. Sci. Part. B 2013, 51, 303-310. [CrossRef]

27. Yu, F.; Chen, S.; Chen, Y.; Li, H.; Yang, L.; Chen, Y.; Yin, Y. Experimental and theoretical analysis of polymerization reaction process on the polydopamine membranes and its corrosion protection properties for 304 Stainless Steel. J. Mol. Struct. 2010, 982, 152-161. [CrossRef]

(C) 2019 by the authors. Licensee MDPI, Basel, Switzerland. This article is an open access article distributed under the terms and conditions of the Creative Commons Attribution (CC BY) license (http://creativecommons.org/licenses/by/4.0/). 